1 Universidade Federal da Bahia (UFBA), Instituto de Saúde Coletiva (ISC) Salvador (BA), Brasil. schaves@ufba.br

2 Secretaria de Saúde do Estado da Bahia (Sesab) - Salvador (BA), Brasil. Universidade Federal da Bahia (UFBA), Instituto de Saúde Coletiva (ISC) Salvador (BA), Brasil. gerluce.alves@gmail.com

3 Universidade do Estado da Bahia (Uneb) - Salvador (BA), Brasil. Universidade Federal da Bahia (UFBA), Instituto de Saúde Coletiva (ISC) - Salvador (BA),

Brasil.

thais.aranha@gmail.com

\section{Avaliabilidade do Projeto de Mobilização Social para Prevenção e Controle da Dengue no Estado da Bahia.}

\author{
Evaluability of the Social Mobilization Project for Prevention and \\ Control of the Dengue in Bahia
}

Sônia Cristina Lima Chaves ${ }^{\mathbf{1}}$, Gerluce Alves Pontes da Silva ${ }^{\mathbf{2}}$, Thais Régis Aranha Rossi ${ }^{\mathbf{3}}$

RESUMO Foi realizado um estudo de avaliabilidade do Projeto de Mobilização Social para Prevenção e Controle da Dengue no Estado da Bahia, assim como foi descrito o modelo de intervenção prático. Foram conduzidas entrevistas junto a informantes-chave, análise documental e observação participante. Os resultados apontam que o Projeto pode ser considerado implementado, e seus principais resultados se situaram em torno da mudança do enfoque sobre dengue na pauta da mídia, bem como da maior integração dos entes federados e entre os Agentes Comunitários de Saúde e os Agentes de Endemias. Aspectos relacionados ao contexto municipal foram vistos como obstáculos para o alcance dos resultados esperados.

PALAVRAS-CHAVE Participação comunitária. Avaliação em saúde. Dengue. Política de Saúde.

\begin{abstract}
An evaluability study of the Project Social Mobilization for Dengue Prevention and Control in the State of Bahia was performed, and the practical intervention model was described. Data collection involved interviews with key informants, documentary analysis and participant observation. The results indicate that the Project can be considered implemented, and its main results are related to the change of focus on dengue in the media's agenda, as well as a greater integration of federal entities, and between the Community Health Workers and the Endemic Agents. Aspects related to the municipal context were seen as obstacles to the achievement of the expected results.
\end{abstract}

KEYWORDS Community participation. Health evaluation. Dengue. Health policy. 


\section{Introdução}

Atualmente, no Brasil, a mobilização em torno da necessidade de ações intersetoriais contra a tríplice epidemia de Zika, Dengue e Chikungunya, decorrente do vírus transmitido pelo Aedes aegypti, tem sido enfatizada. As consequências sociais e econômicas decorrentes dos casos de microcefalia são profundas e ainda não completamente conhecidas. A baixa participação da população e a inadequação das estratégias pedagógicas e de comunicação têm resultado, também, em pequena mobilização das populações no sentido de manter o ambiente livre de focos do mosquito, o que é potencializado pelos problemas decorrentes da deficiência do saneamento básico (SANTOS ET AL., 2016).

No caso específico da dengue, cabe destacar que é uma doença sistêmica aguda, de origem viral, que pode levar a diversas manifestações clínicas, desde febre até síndrome de choque potencialmente fatal (BHATT ET AL., 2013). A referida doença é considerada um problema de saúde pública que atinge diversos países no mundo (TEIXEIRA ET AL., 2009; TAUIL, 2002). Estudos apontam que cerca de 50 (SIMMONS ET AL., 2012) a 390 milhões (BHATT ET AL., 2013) de pessoas são infectadas por ano, em, aproximadamente, 100 países (SIMMONS ET AL., 2012).

O Brasil é um país que ocupa uma das primeiras posições no mundo com relação ao número de casos notificados e ao risco de ocorrência da doença (TEIXEIRA ET AL., 2009). As condições socioambientais favoráveis para a propagação do mosquito transmissor permitiram sua dispersão desde a sua reintrodução no País, em 1976 (PIMENTA-JUNIOR, 2005; TAUIL, 2002). Desde então, o vetor mostrou alta adaptabilidade ao ambiente criado pela urbanização rápida, tendo desempenhado papel central na produção da doença o espaço habitado pelo homem (TEIXEIRA ET AL., 2009).

Os habitats para o Aedes aegypti colocar seus ovos são de grande disseminação nas condições atuais de vida urbana e podem ocorrer tanto em áreas com saneamento básico deficiente quanto adequado (TEIXEIRA ET AL., 2009; TAUIL, 2002), não sendo a pobreza um fator de risco preponderante (FLAUZINO; SOUZASANTOS; OLIVEIRA, 2009). Estudo que analisou a progressão do vírus da dengue na Bahia, no período de 1994 a 2000, apontou circulação do vírus em todas as zonas climáticas do estado, ressaltando o elevado poder do mosquito de se adaptar na região árida e semiárida, bem como uma maior intensidade de casos nas regiões úmidas e semiúmidas do litoral (MELO ET AL., 2010). Uma avaliação conduzida sobre o impacto das ações de combate ao mosquito, em Salvador (BA), verificou efetividade muito reduzida das ações de combate vetorial, nos anos de 1998 e 1999, tendo sido destacada a insuficiência de atividades de educação/informação, para que a população pudesse participar continuamente da destruição/proteção de depósitos que podem se transformar em ambientes propícios à proliferação do mosquito (TEIXEIRA ET AL., 2002).

Como o combate ao Aedes aegypti representa um grande desafio e apresenta muitos pontos críticos, o governo brasileiro vem implementando um conjunto de intervenções, atualmente consolidadas pelo Programa Nacional de Controle da Dengue (PNCD). Entre os diversos componentes desse programa, encontra-se o de 'Educação em saúde, comunicação e mobilização social', conforme indica o modelo lógico do programa elaborado por Pimenta-Júnior (2005). Esse componente tem como atividades instituir Comitê Municipal de Mobilização, implantar ações educativas na rede de ensino e dispor de equipe para realizar as ações de educação em saúde e mobilização, para que se atinja a participação da população na fiscalização das ações executadas e mudanças de práticas para manter o ambiente doméstico preservado de Aedes aegypti. Assim, um resultado esperado seria a redução de criadouros potenciais, contribuindo para o alcance do índice de infestação $<1 \%$.

$\mathrm{Na}$ Bahia, foi formulado um projeto de mobilização social para prevenção e controle 
da dengue, conhecido como Movimento Bahia Unida Contra a Dengue. Sua implementação teve início em julho de 2010. Essa intervenção teve o propósito de

superar as dificuldades e limitações das ações isoladas e episódicas contra a Dengue, formando uma rede coesa, dinâmica, dotada de capilaridade e sustentabilidade para promover a incorporação das ações de prevenção e controle na rotina dos cidadãos, mesmo fora dos períodos epidêmicos, quando tradicionalmente se concentram as campanhas contra a disseminação da doença. (FLEM, 2010, P. 3).

Esse objetivo almejava ser alcançados a partir de uma rede participativa e dinâmica com distintos atores sociais capazes de desenvolver ações de supressão dos criadouros dos mosquitos nos domicílios. O presente estudo visou realizar uma avaliabilidade e descrever o modelo de intervenção prático do Projeto de Mobilização Social para Prevenção e Controle da Dengue no Estado da Bahia.

\section{Metodologia}

Foi conduzido um estudo de avaliabilidade que pode ser considerado um processo voltado para clarificar os desenhos dos programas, explorando sua realidade e, se necessário, ajudando a redesenhá-lo (ROSSI; LIMPSEY; FREEMAN, 2004; PATTON, 2002). Os estudos de avaliabilidade envolvem a descrição do modelo do programa, avaliação de seus propósitos e de quão avaliável é o programa (ROSSI; LIMPSEY; FREEMAN, 2004). Além do estudo de avaliabilidade, realizou-se a descrição do funcionamento do programa na prática. Foram eleitos dois entre os doze municípios participantes, desde o projeto piloto, para realização de entrevistas e observação in loco da intervenção implementada. As razões para essa seleção decorreram de duas reuniões realizadas com os stakeholders, aqueles atores interessados no projeto, aqui, relacionados aos gestores estaduais. Estes consideraram que um dos municípios apresentava elementos de provável êxito no projeto, sendo considerado de médio porte. $\mathrm{O}$ segundo município alvo de análise foi uma indicação da área técnica da gestão estadual.

Foram realizadas 20 (vinte) entrevistas com informantes-chave da equipe executora $(n=4)$, técnicos da Secretaria de Saúde do Estado da Bahia (Sesab) ( $\mathrm{n}=3$ ), 1 coordenador municipal, 5 articuladores do município A, 2 coordenadores municipais e 5 articuladores do município B. Foram desenvolvidos roteiros de entrevistas adaptados à função exercida na gestão estadual ou municipal e na articulação, assim como foi relacionado ao papel desempenhado pelo ator. As perguntas do instrumento semiestruturado perpassavam o cargo, a formação, as concepções de intersetorialidade, rede, parceria; o entendimento sobre o projeto, suas responsabilidades e ações desenvolvidas, os objetivos do projeto, o alcance dos objetivos, as facilidades e dificuldades, o acompanhamento, os principais resultados alcançados e aspectos para aprimoramento.

As entrevistas foram gravadas e transcritas, bem como foi solicitada a assinatura do Termo de Consentimento Livre e Esclarecido para estudos em humanos. O número de entrevistados respeitou o princípio da saturação das informações. Além disso, foram analisados sete relatórios técnicos de viagem nos municípios. Foi realizada uma triangulação das evidências, especialmente entre os diversos agentes, bem como a partir da análise documental. Foi realizada observação participante, com foco no funcionamento do programa, e indagou-se se as atividades previstas estão sendo realizadas e de que forma. Os dados foram processados, codificados, organizados em matrizes e analisados segundo suas categorias. O presente estudo foi aprovado pelo Comitê de Ética em Pesquisa do Instituto de Saúde Coletiva da Universidade Federal da Bahia, $\mathrm{n}^{\mathrm{0}}$ 60525616.4.0000.5030. 


\section{Etapas do estudo}

a) Clarificação dos objetivos do programa por meio de revisão da documentação do programa e entrevistas junto a gestores e profissionais envolvidos na sua execução (aqueles com interesse na intervenção ou em sua avaliação);

b) Elaboração do modelo lógico do programa, com atenção especial para as relações entre o problema, seus determinantes, o que o programa faz (a intervenção) e o que se espera que alcance (os resultados). A avaliação de um programa social quanto à coerência entre seu planejamento e sua implementação exige a construção de um modelo lógico que explicite seus objetivos, ações e metas. Ele representa um recorte feito da realidade (MEDINA ET AL., 2005). O modelo lógico de um programa é definido, também, como uma imagem do trabalho realizado por uma organização. Ele atrela resultados às atividades ou aos processos de um programa, conjugando os pressupostos teóricos;

c) Descrição do funcionamento do programa na prática. Nesta etapa, pretendeu-se estimar como o programa está funcionando na prática (o modelo da intervenção prático), o que se sabe e o que não se sabe sobre ele;

d) Elaboração de recomendações. Finalmente, foi elaborado um conjunto de recomendações capaz de identificar áreas para melhoria do programa; identificar componentes do programa sobre os quais não se tem informação (perguntas para avaliação); identificar quais questões de avaliação são plausíveis e úteis para o mesmo.

A opção de apresentar os resultados junto aos dois municípios decorreu do fato de não haver diferenças significativas entre eles na implementação da intervenção. Os problemas foram muito similares no que se refere ao modelo na prática e nos resultados já alcançados.

\section{Resultados e discussão}

O Projeto de Mobilização Social para Prevenção e controle da Dengue no Estado da Bahia pode ser considerado implementado com vistas à sua avaliação sistemática. Em resposta às principais questões formuladas, observou-se que a rede de mobilização é capaz de produzir o(s) resultado(s) esperados. Contudo, ela não se mantém sem produtor social presente no nível local, sendo sugeridos o deslocamento do foco da rede e a redefinição de produtores, editores e reeditores. O produtor social pode ser entendido como uma pessoa ou uma instituição com responsabilidade para viabilizar o movimento, com a intenção de mudança da realidade e capacidade para assegurar que o processo de mobilização possa ocorrer (TORO; WERNECK, 1996). Neste sentido, o produtor social deve situar-se no nível municipal e estabelecer interlocução com outros atores.

A integridade da implantação das etapas da intervenção não foi observada, ou seja, nem todos os componentes da intervenção descritos no papel foram implementados. Aqueles com maiores problemas foram: o diagnóstico situacional dos bairros, identificação e sensibilização de lideranças locais, seleção e capacitação de articuladores, elaboração dos Planos de Mobilização Social de cada bairro, a realização complexa dos faxinaços e o acompanhamento do projeto, incluindo o uso do Sistema de Informações da Mobilização Social (Sismob). Mais do que da equipe produtora, as características dos governos locais dificultaram ou facilitaram a integridade das ações do projeto, a exemplo da ausência de estrutura e recursos para desenvolver as ações do projeto por uma gestão municipal, o que causou dificuldades, e apoio por parte dos gestores do outro município, o que trouxe facilidades. Esses aspectos também foram apontados no estudo de Rossi e Chaves (2016), no qual 
foi analisada a implementação da política de saúde bucal, tendo sido o projeto e a capacidade de governo aspectos fundamentais para o êxito das ações nos municípios.

\section{Modelo lógico preliminar e modelo lógico na prática}

O modelo lógico preliminar foi construído a partir da leitura dos documentos-base do projeto (figura 1). Após a formulação do modelo lógico preliminar, o mesmo foi apresentado aos gestores e executores na busca de uma verificação se a perspectiva apreendida pelas autoras, a partir dos documentos, correspondia àquela que está na representação dos profissionais e gestores do projeto. Aspectos da teoria da produção social, implícita na proposta, também foram objeto de reflexão do grupo. Ao final, concordou-se que o projeto tem como objetivo a formação e a manutenção de redes de mobilização sustentáveis para as ações de prevenção e controle da dengue nos municípios-alvo. Para a formação de redes, aspecto que também foi objeto de problematização conceitual por parte do grupo, devem ser seguidas algumas etapas sugeridas, num total de dezoito. Os resultados esperados ainda se apresentaram difusos e pouco claros por parte dos participantes da reunião, bem como a identificação de indicadores mensuráveis para o acompanhamento do projeto.

A figura 2 apresenta o modelo lógico elaborado após análise dos dados coletados no estudo. Do conjunto das evidências, observou-se que o modelo lógico na prática apresenta algumas singularidades, especialmente no que se refere aos resultados intermediários, muitos deles não confirmados. Observou-se, também, uma baixa integridade no seguimento dos dezoito passos, representado pelas setas na figura 1 , que foi então substituído por um conjunto de quinze componentes, compreendidos como a expansão da teia social da rede. Assim, as setas não foram representadas na figura 2, tendo em vista que a inflexibilidade no passo a passo engessou a visão estratégica sobre os diferentes caminhos a serem seguidos para atingir o objetivo em cada realidade local, muitas vezes distinta. As principais evidências do modelo lógico na prática serão descritas nos tópicos a seguir. 
Figura 1. Modelo lógico preliminar do Projeto Movimento Bahia Unida Contra a Dengue segundo documentos-base

Problema: Ações de mobilização social insuficientes para o controle da dengue em municípios selecionados no estado da Bahia.

Objetivo: Promover a mobilização social para a prevenção e o controle da dengue em municípios do estado da Bahia, identificados pela Sesab como prioritários por apresentarem maiores índices de infestação do mosquito transmissor da dengue.

Componentes principais

\begin{tabular}{l}
\hline \multicolumn{1}{|c|}{ PREPARAÇÃo } \\
Atividades \\
\hline $\begin{array}{l}\text { Constituição de unidade } \\
\text { gestora e capacitação } \\
\text { da equipe }\end{array}$ \\
\hline
\end{tabular}

Conhecimento prévio do município e contatos preliminares

com lideranças locais

\begin{tabular}{l}
$\begin{array}{l}\text { Preparação de material } \\
\text { didático-pedagógico } \\
\text { promocional }\end{array}$ \\
\hline
\end{tabular}

promociona

Desenvolvimento do Sistema

\section{Resultados intermediários}

\section{Adesão de diversos}

segmentos da imprensa

com apoio expressiv

com

Maior transparência para a

população das ações de

prevenção e controle da

dengue através das redes

sociais e dos sites.

Resultado Final

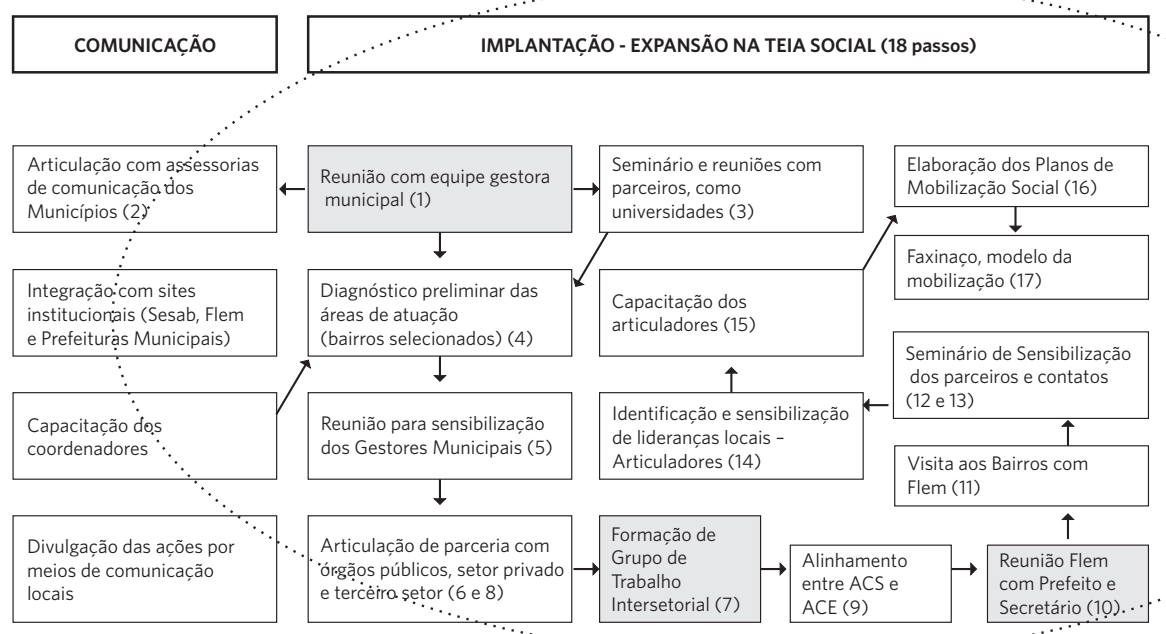

ACOMPANHAMENTO
$\ddots \quad$ E AVALIACÃO

$\because \ddots$

Acompanhamento presencial: (Reuniões quinzenais dos $\because$. articuladores/coordenador/ Encontros com a equipe Flem no município) (18)

Acompanhamento virtual (Sismob)

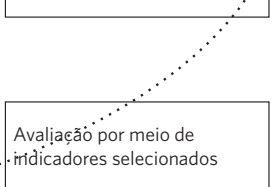

\section{Capacitação de cidadãos de \\ diversos segmentos da}

sociedade civil.

\section{Qualificação do debate sobre}

os determinantes dos

criadouros de mosquito.

Estreitamento das relações

ACS/ ACE.
Intensificação das ações de articulação e parceria entre governo estadual, municipal e sociedade civil.

Participação das pessoas em
mutirões e faxinaços;
visita às casas.

Observação das ações

realizadas e com orientações

oportunas.

Aferição das atividades

Envolvimento de parceiros

potenciais.

desenvolvidas.

Avaliação da qualidade do trabalho e eventual

necessidade de modificações. 
Figura 2. Modelo lógico na prática do Projeto Movimento Bahia Unida Contra a Dengue a partir das entrevistas, análise dos relatórios e observação

Problema: Ações de mobilização social insuficientes para o controle da dengue em municípios selecionados no estado da Bahia.

Objetivo: Promover a mobilização social para a prevenção e o controle da dengue em municípios do estado da Bahia, identificados pela Sesab como prioritários por apresentarem maiores índices de infestação do mosquito transmissor da dengue.

Componentes principais

PREPARAÇÃO
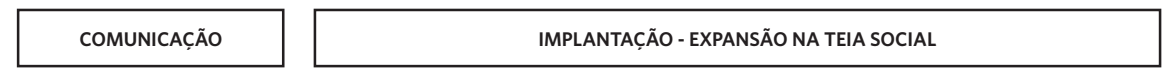

ACOMPANHAMENTO
E AVALIAC̣ÃO

Atividades

\begin{tabular}{|l|}
\hline $\begin{array}{l}\text { Constituição de unidade } \\
\text { gestora e capacitação } \\
\text { da equipe }\end{array}$ \\
\hline
\end{tabular}

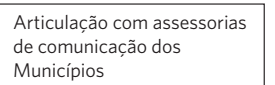

Municípios
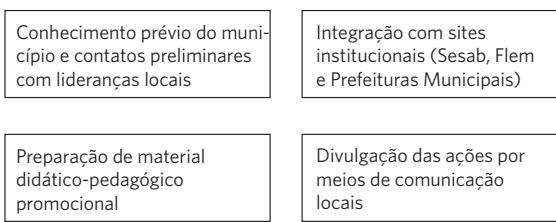

e Prefeituras Municipais)

\section{Divulgação das ações por} meios de comunicação locais
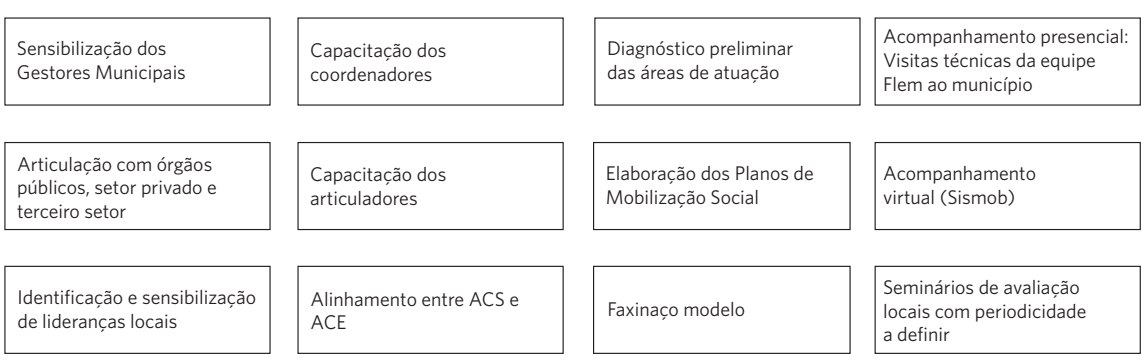

promocional

Desenvolvimento do

Sismob

Resultados intermediários

Informações sobre dengue

na mídia

Divulgação das ações de

prevenção e controle da

dengue por meio das redes

sociais e sites.

\section{Articulação entre setores dos governos estadual e municipal}

Envolvimento de parceiros potenciais.

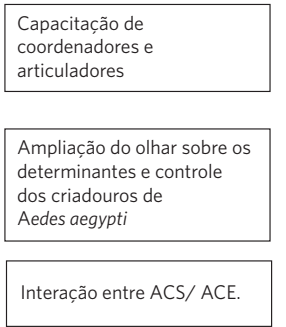

Diagnóstico sucinto e

preliminar das áreas de

atuação. Participação das pessoas em
mutirões e faxinaços.
Equipes locais estimuladas

Aferição das atividades desenvolvidas.

\section{Resultado Final}

Formação temporária de rede de mobilização para as ações de prevenção e controle da dengue nos municípios selecionados.

\section{OBJETIVOS E CONCEPC̣ÕES COMPARTILHADAS}

Houve consenso quanto ao objetivo principal do projeto, que é a formação de redes no sentido de permitir maior mobilização da população no controle do vetor. A maioria dos entrevistados referiu como objetivo do projeto a mobilização da população para o controle da dengue. Contudo, havia dúvidas sobre sua manutenção sem a presença do produtor social no nível local. Essas dúvidas estão diretamente relacionadas à teoria subjacente do programa - ou seja, aos pressupostos que sustentam a proposta -, que são aqueles das redes de compromisso social (INOJOSA, 1999). Foi apontado que produtores da rede de mobilização social não podem se situar longe do município onde essa intervenção se desenrola. O deslocamento do foco da rede, redefinindo produtores, editores e reeditores, é apontado por alguns agentes.

A minha percepção é que se a gente não mantém o município vinculado a alguma estrutura de comando [...], então há uma desmobilização total. 
Essa sonhada sustentabilidade, que é a coisa mais importante do projeto, ela não se concretiza se não houver alguém que conduza esse processo, então, a rede, na verdade, ela não se sustenta se não houver alguém de referência para estar lembrando. (Sesab 1).

Concepções compartilhadas sobre intersetorialidade, constituição de redes e parceria apontaram algumas divergências importantes. Enquanto, para alguns, a intersetorialidade é a corresponsabilização e a ação conjunta de setores governamentais, para outros, ela se amplia com a ação de setores não governamentais, como o setor privado, produtivo. Entretanto, de modo geral, foi descrita como uma teia, uma cadeia com pontos interdependentes em torno de um tema comum, a mobilização social para o controle da dengue. Conforme afirma Toro e Werneck (1996), a rede resultante é uma teia de múltiplos fios, que pode se espalhar indefinidamente para todos os lados, sem que nenhum de seus nós possa ser considerado principal ou central, nem representante dos demais. Cabe questionar se é possível a existência de redes sem responsáveis.

O papel da fundação que executa o projeto, a Fundação Luís Eduardo Magalhães (Flem), poderia ser, essencialmente, o de facilitadora da intercomunicação, e não de dirigente, comandante ou coordenadora da rede, respeitando o princípio defendido por Toro e Werneck (1996) de que a função principal daqueles que promovem ou lideram um processo de mobilização é permitir a circulação de informações para funcionamento de uma rede.

\section{ASPECTOS DO DESENHO DA INTERVENC̣ÃO: O MODELO NA PRÁTICA}

O aspecto inovador da intervenção é reconhecido por boa parte dos agentes envolvidos em sua implementação. Há referências claras à mudança no modo de trabalhar no território. [o projeto] teve, assim, uma função bem diferenciada do que nós costumávamos atuar [...] 0 agente entrava e limpava sua residência para fazer o serviço que é pertinente, mas é fundamental a participação do morador. Com essa nova visão [...], as coisas foram sendo colocadas para o morador através dos articuladores dos bairros [...], e esse articulador tinha a função de atuar diariamente com seu vizinho, o morador do seu bairro. [...] era fundamental que essa atividade fosse diária, pelo menos de rotina. (Coordenador 1a).

Chamou a atenção o excesso de passos para atingir o objetivo maior, que é a formação de redes de mobilização. Observouse que, ainda que isso seja considerado nas falas, há rigidez dos passos a seguir, sem verdadeiro aprofundamento da realidade municipal, ficando apenas no discurso, na retórica, a percepção das diferenças dos contextos municipais na implementação do projeto. O contexto municipal foi visto como obstáculo para o alcance dos resultados esperados e, por outro lado, é o único capaz de garantir a manutenção da rede, caracterizando-se, portanto, um paradoxo fundamental a ser equacionado.

[...] eu acho que nosso maior problema de princípio, até hoje, em relação à população, é a questão cultural mesmo. O povo [...] é acomodado não só em relação à dengue [...]. O pessoal só se apavora quando vê $[. .$.$] todo mundo com dengue,$ morrendo [...]. Quando chegou a mobilização, nós começamos a mostrar o papel do morador. $E$, quando passa verão, que para um pouco de se falar de dengue, você volta na casa desse morador e acha tudo desfeito. [...]. (Coordenador 2a).

$\mathrm{O}$ apoio ao projeto variou de acordo com o gestor no governo. Em um dos municípios, não se obteve apoio no primeiro momento, enquanto, no outro, a primeira fase foi a mais promissora. Havia uma crítica entre todos os segmentos com relação à falta de apoio dos gestores locais, considerada como o grande entrave para o sucesso do projeto, 
especialmente no que se refere ao enfrentamento dos macrodeterminantes e, também, das demandas da população com relação ao papel do Estado. O apoio institucional estatal foi considerado fundamental.

Os relatórios consultados reforçam os achados. Há neles, ainda, referência à ausência dos convidados nos eventos programados, pouca disponibilidade de tempo ou choque de agendas. Além disso, discussões de temas trabalhistas dos agentes de saúde e educadores tomam parte da agenda das reuniões realizadas. Registrou-se, ainda, a pouca autonomia dos coordenadores.

Com relação aos articuladores, foram citadas diversas atividades para mobilização, contudo, nem sempre com possibilidade de continuidade. A realização de 'faxinaços' ocorreu de forma pontual em ambos os municípios. Além disso, o faxinaço também revelou as questões de controle de lixo não doméstico, sendo um momento dos moradores de se livrar do entulho acumulado não recolhido pelo poder público.

Nos relatórios analisados, os faxinaços parecem assumir um papel central, e, para essa ação, são relatadas tanto atividades de rotina do Programa de Controle da Dengue (PCD) como outras realizadas pelos Agentes Comunitários de Endemias (ACE), que não fazem parte das suas atribuições profissionais. Parece haver uma maior integração entre ACE e Agentes Comunitários de Saúde (ACS) nesses eventos, e alguns deles contaram com pouca participação da comunidade ou mesmo dos ACE.

Além da falta de apoio institucional e de resposta às demandas da população, citaram-se como dificuldades para implementação das atividades programadas: a comodidade dos moradores, a agenda de eventos incompatível com as atividades cotidianas dos articuladores, a insuficiente articulação no processo e a desestruturação dos serviços de saúde.

A seleção de coordenadores e articuladores com vínculo na vigilância municipal favoreceu o projeto diante de um conhecimento maior dos problemas vivenciados, no entanto, observou-se na fala dos entrevistados, em alguns momentos, pouca clareza com relação às ações que seriam específicas do projeto e àquelas da rotina do Programa de Controle da Dengue Municipal. Em um dos municípios, a seleção e a manutenção dos coordenadores passaram por muitos entraves devido aos problemas de gestão, o que causou desmotivação e fragmentação da equipe. Quanto aos articuladores, identifica-se como obstáculo à sustentabilidade do projeto o grande número de articuladores ACE e ACS, o que decorre da dificuldade de captação de lideranças nos bairros para essa função.

Ressaltou-se que o entendimento da função do coordenador variou entre os entrevistados do município de mero executor de tarefas a de ser o responsável por encaminhar as demandas da população à gestão municipal. Em um dos municípios, a coordenação criou metodologia própria e trabalhava no planejamento das atividades. A articulação entre coordenadores e articuladores variou entre os municípios estudados: em um deles, quatro articuladores entre os cinco entrevistados mencionaram nominalmente a coordenação; no outro, houve divergência entre os segmentos a esse respeito. Quanto ao acompanhamento da equipe de apoio do projeto, as visitas técnicas presenciais foram concentradas em períodos curtos, com muitas atividades, sobrecarregando a agenda. Pareceu existir, em alguns momentos, certa imposição de agenda para os encontros presenciais.

\section{Análise do sistema de informação da mobilização social: o Sismob}

O documento de passo a passo do Projeto de Mobilização Social para Prevenção e Controle da Dengue no Estado da Bahia define o Sismob como um software disponibilizado pela Sesab e desenvolvido pela 
Flem, especialmente para a mobilização, com o intuito de registrar as atividades, facilitar a comunicação e trocar ideias e informações entre os envolvidos, permitindo o acompanhamento das ações realizadas.

O Sismob possibilitava o cadastro de agentes da mobilização, como coordenadores e articuladores, bem como dos bairros e municípios contemplados pelo Projeto de Mobilização Social para Prevenção e Controle da Dengue no Estado da Bahia. O sistema apresentava informações sobre as Diretorias Regionais de Saúde (Dires), sobre as zonas de informação e instituições parceiras.

O Sistema disponibilizava, entre o que se intitulava 'ações de mobilização', as ações realizadas pelos bairros, pelos municípios (quando envolvia mais de um município), ações pendentes para validação e cancelamento de ações. As ações de mobilização poderiam ter mais de uma atividade, a exemplo de panfletagens, palestra, música etc. Nesse sentido, poderiam ser consultadas por período, por atividade, ações canceladas, ranking de ações, detalhes das ações, informações das pessoas, tempo de registro das ações, índice de instituições por ação, quantitativo de acessos, quantitativo gerencial, relatório, tipo de articulador e mapa. Também poderiam ser consultados detalhes das ações, quantidades das ações e quantidades por perfil. Esse sistema exportava relatórios, acessava links e realizava associação com as redes sociais.

Os atores entrevistados da Flem e da Sesab mencionaram a importância do Sistema para o monitoramento das ações nos municípios, tendo servido como comprovação de ações de combate à dengue em um dos municípios do projeto junto ao Ministério Público. Contudo, percebeu-se que ele tem sido mais um depositário de ações do que ferramenta de monitoramento e avaliação do projeto propriamente dito. Os próprios relatórios da equipe executora não utilizavam a potencialidade do sistema para avaliação e monitoramento remoto da condução da intervenção no nível local. Foram também apontadas lacunas, como ações de mobilização que já eram realizadas antes do projeto e que hoje estão no Sismob. Foi destacada uma preocupação com a continuidade e a manutenção do Sistema após o término do projeto, tendo em vista que a Flem exercia esse papel no momento da investigação.

Muitos entrevistados nos municípios destacaram a baixa ou nenhuma utilização do sistema. Ressalta-se que, nos municípios visitados, a maioria expressiva das ações de mobilização não era lançada no Sismob por articuladores, como preconizado pelo projeto, mas pelos coordenadores municipais. Os coordenadores relataram sobrecarga de trabalho e ausência de informações sobre o Sismob ou dificuldades com informática. Nesse sentido, assumiram que muitas ações realizadas não constavam no Sismob. Atores entrevistados nos dois municípios citaram lacunas na capacitação dos articuladores para utilização do Sismob, o que foi relacionado à falta de utilização do Sistema.

Os articuladores e um coordenador relataram obstáculos a serem superados na capacitação realizada pela Flem nos municípios, a fim de apresentar o Sismob. Afirmou-se que a carga horária é insuficiente e a metodologia necessita ser revista. Ademais, trouxeram como sugestão que essa capacitação pudesse ser realizada nos bairros ou por grupos de bairros.

... a gente não teve mais contato com ninguém [...] praticamente o município parou, e a gente também acabou também... a gente só fez aquele projeto de mobilização lá e, depois, não fizemos mais nada. A gente deu uma parada... (Articulador 2a).

Outro aspecto importante relatado seria $o$ conceito de ações de mobilização. Foi constatado no sistema o registro de ações de bloqueio que não se constituem como tal. Assim, seria necessário estabelecer um glossário, dentro do Sismob, para leitura daqueles que 
irão inserir os dados, com definição clara do que se entende por ações de mobilização, bem como outros termos utilizados.

$\mathrm{Na}$ visita aos municípios, deparou-se com muita dificuldade para encontrar articuladores ativos. Em sua maioria, esses apresentavam status ativo no relatório de articuladores exportado do Sismob, mas já haviam deixado o projeto. A falta de atualização também se refletiu no fato de a maioria dos articuladores no Sistema não possuir registrada a sua atribuição (ser morador, ACS ou ACE). Ademais, na descrição das ações, existia muita diversidade na forma de preenchimento. Era importante que houvesse padronização quanto ao preenchimento dos campos e detalhamento das ações para que fosse possivel compreender quais atividades de mobilização social foram realizadas.

\section{PROPOSIÇÃO DE INDICADORES PARA MONITORAMENTO E AVALIAC̣ÃO}

A qualidade dos processos de coleta, processamento, análise e transmissão da informação é fundamental para o monitoramento e a avaliação de uma intervenção. Foi identificado um conjunto de lacunas que podem ser equacionadas na transformação de um dado, presente no Sismob em 'informação útil'. A transformação de um dado em informação exige, além da análise, a divulgação. Deve considerar possíveis recomendações para a ação.

O 'Indicador' é sempre um índice que reflete uma situação determinada, a partir da relação entre variáveis, que permite medir mudanças e determinar o grau de cumprimento das metas da intervenção. É frequentemente um valor relativo. Nesse sentido, os indicadores para monitoramento ou avaliação de uma intervenção devem ser medidas sintéticas que refletem determinadas características da estrutura, do processo ou do resultado de uma intervenção (DONABEDIAN, 1980).

O quadro 1 descreve os indicadores já propostos pela Flem, sua definição e suas observações a respeito da viabilidade do uso dos mesmos para o monitoramento/avaliação do projeto. Parte deles é valor absoluto, o que reflete sua fragilidade. Outros não podem ser considerados propriamente como indicadores, e, sim, sugestões de focos/aspectos do projeto que devem ser monitorados/avaliados (quadro 2).

Quadro 1. Comentários sobre análise dos indicadores e definições fornecidas, sugeridos pela equipe executora, com definição, propostas e observações

\begin{tabular}{|c|c|c|}
\hline Indicadores & Definição & Observações \\
\hline $\begin{array}{l}\text { Quantidade de articuladores } \\
\text { moradores dos bairros ( } 30 \text { por } \\
\text { município) }\end{array}$ & $\begin{array}{l}\text { Adesão da sociedade civil, através do envol- } \\
\text { vimento voluntário e a participação popular } \\
\text { efetiva na formulação, no planejamento e na } \\
\text { execução das ações de prevenção e controle da } \\
\text { Dengue nos bairros selecionados. }\end{array}$ & $\begin{array}{l}\text { Não é possível mensurar a 'adesão da sociedade civil' e 'a } \\
\text { participação popular efetiva' apenas com a quantidade/nú- } \\
\text { mero de articuladores por bairro. } \\
\text { O número absoluto, caso fosse atualizada a manutenção } \\
\text { de atividade por parte do articulador, só poderia indicar o } \\
\text { 'número de articuladores cadastrados ativos'. }\end{array}$ \\
\hline $\begin{array}{l}\text { Quantidade de parceiros privados } \\
\text { (empresários, comerciantes, asso- } \\
\text { ciações e sindicatos, entre outros) }\end{array}$ & $\begin{array}{l}\text { Mudança de postura dos atores envolvidos, } \\
\text { gerando uma conscientização das outras áreas } \\
\text { sobre a sua corresponsabilidade nas ações de } \\
\text { prevenção e controle da Dengue. }\end{array}$ & $\begin{array}{l}\text { Não é possível mensurar 'mudança de postura dos atores } \\
\text { envolvidos' e 'conscientização das outras áreas sobre a sua } \\
\text { corresponsabilidade' apenas com o número de parceiros } \\
\text { privados. } \\
\text { O número absoluto, caso fosse atualizada a manutenção de } \\
\text { atividade por parte do parceiro, só indicaria o 'número de } \\
\text { parceiros cadastrados ativos'. }\end{array}$ \\
\hline
\end{tabular}




\section{Quadro 1. (cont.)}

Intersetorialidade

Participação e corresponsabilidade da comunidade
Formação do Grupo de Trabalho Intersetorial Captação e envolvimento de parceiros órgãos públicos estaduais e municipais.

Quantidade de pessoas participando nos faxinaços e número de casas visitadas.

Não descrito.

Quantidade de cidadãos de diversos segmentos da sociedade civil capacitados, como 'Agentes Multiplicadores da Mobilização'

Quantidade de matérias em jornais, sites, blogs

Integração do trabalho dos Agentes Comunitários de Saúde (ACS) e os Agentes de Controle de Endemias (ACE), na prevenção e no controle da dengue

Resultado de interações e compartilhamentos nas redes sociais

Reuniões do Comitê Estadual de Mobilização Social para Prevenção e Controle da Dengue no Estado da Bahia

Participação efetiva da Gestão Pública Municipal

Número de Ações de Mobilização Não descrito. realizadas e cadastradas no Sismob
Clipagem e tempo concedido para entrevista de forma gratuita em veículos de comunicação local.

Não descrito.

Facebook, Twitter, Youtube e site.

Quantidade, frequência e qualidade da participação de membros integrantes.

Distribuição de responsabilidade e atribuições do Projeto entre as diversas áreas da saúde. Trabalho intersetorial das secretarias municipais atendendo e resolvendo problemas que determinam os macrodeterminantes para a dengue.

Este não seria um indicador, e, sim, uma categoria a ser avaliada,

Por outro lado, só a Formação do Grupo de Trabalho Intersetorial não permite aferir o 'envolvimento de parceiros órgãos públicos estaduais e municipais',

Este não seria um indicador, e, sim, uma categoria a ser avaliada.

O 'número de participantes' e o 'número de casas visitadas' podem apontar para a 'corresponsabilidade' durante os faxinaços, mas não a manutenção das atividades de prevenção da dengue nos intervalos entre os mesmos, como previsto para o projeto.

São os articuladores? - Como mensurar? Rever a denominação 'Número de cidadãos de diversos segmentos da sociedade civil que participaram de treinamentos' para 'Agentes Multiplicadores da Mobilização'. Ter participado de um treinamento não indica 'ser capacitado' para atuar como 'Agente Multiplicador da Mobilização'.

Há viabilidade de se monitorar por meio da técnica de 'clipagem' as notícias veiculadas na mídia e o tempo disponibilizado? Quem ficaria responsável? Qual o tempo disponível?

Este não seria um indicador, e, sim, uma categoria a ser avaliada.

A avaliação da integração implicaria a elaboração de questionários e trabalho de campo específicos

O indicador seria 'Número de interações e compartilhamentos nas redes sociais'. Essa seria uma estatística geral, sem análise da situação local.

Indicadores possíveis seriam 'Número de Reuniões do Comitê Estadual de Mobilização Social para Prevenção e Controle da Dengue no Estado da Bahia' e 'Percentual de frequência dos componentes do Comitê'.

A qualidade das reuniões implicaria uma análise de caráter qualitativo das atas de reunião ou de observação das mesmas.

Este não seria um indicador, e, sim, uma categoria a ser avaliada.

A avaliação da 'Participação Efetiva da Gestão Pública Municipal' implicaria a elaboração de questionários e trabalho de campo específicos.

No texto deste relatório são levantados vários questionamentos relacionados à validade deste indicador. 
Quadro 2. Indicadores propostos para o Projeto de Mobilização Social para Prevenção e Controle da Dengue no Estado da Bahia, a partir da avaliabilidade realizada

\begin{tabular}{|c|c|}
\hline Indicadores & Observações \\
\hline Diagnóstico do contexto municipal & \% de domicílios com esgotamento sanitário e \% de domicílios com água encanada, disponíveis no IBGE. \\
\hline Articuladores Ativos & \% de articuladores ativos em relação ao total de articuladores cadastrados por município ou bairro. \\
\hline $\begin{array}{l}\text { Plano de Ação por Bairro registrado } \\
\text { no Sismob }\end{array}$ & \% de Plano de Ação por Bairro registrada no Sismob em relação ao total de bairros contemplados no projeto. \\
\hline Média de faxinaços anuais & Média de faxinaços por ano por município e bairros. \\
\hline Alcance da meta de faxinaços & \% de Alcance da meta de faxinaços (meta=4 faxinaços por bairro, 40 faxinaços por ano por município). \\
\hline $\begin{array}{l}\text { Proporção de faxinaços entre as } \\
\text { ações desenvolvidas }\end{array}$ & Proporção de faxinaços em relação às demais ações de mobilização. \\
\hline Cobertura de faxinaços & $\begin{array}{c}\mathrm{x}=\mathrm{n} \text { de bairros com faxinaço } \times 100 \\
\text { Total de bairros }\end{array}$ \\
\hline Ações validadas pelo Sismob & \% de ações executadas que foram validadas no Sismob por município. \\
\hline $\begin{array}{l}\text { Tempo médio de validação pelo } \\
\text { Sismob }\end{array}$ & Tempo médio de validação das ações executadas. \\
\hline Articuladores usuários do Sismob & \% de articuladores que lançam ações em relação ao total de articuladores ativos. \\
\hline
\end{tabular}

No tocante ao uso de indicadores de resultado para monitorar e avaliar as ações, evidências apresentadas no presente relatório indicam que, como formulado, o projeto contemplou todas as atividades preconizadas pelo Programa Nacional de Controle da Dengue para o componente Ações Integradas de Educação em Saúde, Comunicação e Mobilização Social. Podemos citar entre elas a Instituição de Comitê Municipal de Mobilização e a implantação de ações educativas na rede de ensino. Por outro lado, o conjunto de atividades preconizadas pelo PCD para esse componente tem como objetivo fomentar o desenvolvimento de ações educativas para a mudança de comportamento e a adoção de práticas para a manutenção do ambiente domiciliar preservado da infestação por Aedes aegypti, o que contribuiria para a redução de criadouros potenciais e para o alcance do índice de infestação $<1 \%$.
No entanto, para obtenção desses resultados, é fundamental a implantação adequada de outros componentes do PCD, ressaltando-se o de saneamento básico. Com isso, não se pode atribuir a um só componente o alcance de resultados esperados para um conjunto. A disponibilidade de dados para aferição de indicadores de resultado por bairro, unidade de análise que deve ser utilizada para monitoramento/avaliação das atividades do projeto, pois o mesmo assim foi concebido, foi outra dificuldade levada em consideração.

Os relatórios técnicos finais apresentam grande parte do seu conteúdo com informações relacionadas à situação estadual. $\mathrm{O}$ texto dos relatórios dos dois municípios estudados é muito semelhante, não refletindo uma análise do contexto municipal. Os trechos são idênticos, com mudança apenas no nome do município.

Considera-se que as potencialidades do 
Sismob não foram exploradas, com os dados sendo apresentados nos relatórios técnicos para o município como um todo, não se utilizando como unidade de análise os bairros, o que contribuiria para uma melhor visualização dos resultados do projeto. Um ponto a ser repensado seria o ranking das ações para os municípios, bem valorizado nos relatórios, pois não fica bem explicitada a diferença entre atividades e ações alimentadas no Sismob, além do uso da mesma denominação para elas. Além do mais, diversos problemas operacionais podem afetar o registro dessas ações/atividades.

\section{Resultados do projeto}

As evidências apontam como principais resultados do projeto, na percepção dos agentes, a entrada e a permanência da Dengue na pauta da mídia com mudança no enfoque anterior de 'culpabilização' apenas do Estado na resolução do problema. Outros resultados foram a maior comunicação entre os ACS e ACE, entendidos como grupos importantes na prevenção e no controle da dengue frente à comunidade, e a disseminação de informações sobre a prevenção da doença.

Outro resultado foi o estabelecimento da relação entre a Sesab e os municípios, tendo em vista que as Dires apresentam fragilidade na intermediação dessa relação. Nas falas dos representantes do nível municipal, aponta-se o "engajamento da população nos bairros mais problemáticos" (Articulador $5 \mathrm{a}$ ), sendo "[...] o principal resultado [...] a conscientização do morador... Pela primeira vez, o morador se conscientizou [...]" (Coordenador 1a). Cita-se, ainda, como um dos resultados positivos do projeto a rede intersetorial induzida. Observa-se, no entanto, que os articuladores consideram os resultados temporários:

Olha, com relação aos moradores, acho que não surtiu muito efeito, mas, com relação à associação de moradores, eles conseguiram. Eles mesmos absorveram isso, o que para a gente é um ganho: a associação entender que também tem o papel de mudar [...] essa realidade do nosso bairro... Mas, com relação aos moradores, acho que não teve muito efeito, porque a gente ainda vê muita gente com tanque aberto, acumulando lixo nos seus quintais, muita gente ainda irresponsável com relação ao tratamento da água no seu domicílio. (Articulador 2a).

Os relatórios técnicos finais registraram a criação de uma rede de mobilização nos municípios, com incorporação de um número importante de parceiros. No entanto, parece haver pouca participação dos mesmos em eventos convocados.

Entretanto, as falas de entrevistados do nível central apontaram a oferta irregular de água como um obstáculo ao alcance dos objetivos do projeto, tendo em vista que os moradores necessitam realizar o armazenamento de água em recipientes domiciliares, muitas vezes, inadequados. O contexto do município foi citado como um obstáculo para o alcance dos resultados esperados. Além disso, um resultado não esperado foi a ampliação da pressão da população sobre a ação do Estado. Outro entrevistado apontou aspectos negativos, relatando ausência de mobilização e constatação dos vetores em sua comunidade. Um entrevistado reconheceu avanço no projeto, entretanto, destacou que os resultados esperados não foram alcançados.

Em análise sobre as atividades desenvolvidas e os resultados, outro entrevistado, contrapondo-se ao ponto de vista anterior, deu destaque à necessidade emergente de avanço. Pontuou, também, que as atividades propostas pelo projeto não levarão ao alcance dos objetivos. Ademais, houve grande preocupação sobre o momento em que a Flem deixar de ser encarada como produtor social na rede. Estudos que analisam as ações educativas, de comunicação e mobilização social no controle da dengue, 
divergem em seus resultados quanto à efetividade das intervenções.

Um estudo de desenho quase-experimental, desenvolvido em Cuba, assinala que as ações de mobilização, educação e comunicação levaram a mudanças significativas no conhecimento e nas práticas relacionadas ao controle do mosquito (SANCHEZ ET AL., 2005). Entretanto, dois estudos de revisão sistemática (BALLENGER-BROWNING; ELDER, 2009; AL-MUHANDIS; HUNTER, 2011) concluíram que não se pode afirmar que tais intervenções são eficientes na redução dos índices entomológicos, apesar de reconhecerem a importância de mensagens educativas nas comunidades para controle do vetor.

O processo de implantação das ações intersetoriais de mobilização social para o combate à dengue, por meio do Comitê Estadual, no período de 2008 - 2009, foi objeto de estudo na Bahia (LIMA; VILLASBÔAS, 2011). Nesse estudo, os autores indicaram como principal fator facilitador das práticas intersetoriais o apoio político das entidades governamentais, o que não se constatou no presente estudo no âmbito municipal; e, como entraves, citaram a concentração de atribuições sobre um único setor e a não utilização do planejamento como instrumento de trabalho (LIMA; VILLASBÔAS, 2011). Outros autores que analisaram o componente da participação da população nas ações de controle da dengue nos planos de saúde de municípios do estado de São Paulo, no Brasil, constataram que ele não foi priorizado na formulação das políticas municipais para enfrentamento da doença (FERREIRA; VERAS; SILVA, 2009). Assim, para o enfrentamento da dengue, a sustentação e a priorização políticas são fundamentais, assim como o apoio e a mobilização da sociedade são indispensáveis para a disseminação da informação sobre $o$ controle do vetor.

As ações pontuais, os conteúdos descontextualizados das mensagens, a ênfase nas campanhas sanitárias e as estratégias autoritárias foram limites apontados pelo estudo que investigou as ações para prevenção e controle da dengue em um município do Ceará, que corrobora os achados da presente avaliação (SALES, 2008). A introdução de inovações nas práticas de educação e comunicação voltadas para a dengue representa um grande desafio, tendo em vista a necessidade de mudanças nas práticas utilizadas até então. Entretanto, ainda que o poder dessas práticas de induzir a mudanças de comportamento e atitudes seja relativo, elas podem representar um espaço de diálogo democrático e disseminação do conhecimento voltado para o enfrentamento da doença, que deve perpassar um conjunto ampliado de ações intersetoriais (RANGEL, 2008).

\section{Considerações finais}

O presente estudo realizou uma pré-avaliação do Projeto de Mobilização Social para Prevenção e Controle da Dengue no Estado da Bahia. O programa que tratava da formação de redes, no sentido de permitir maior mobilização da população no controle do vetor, apresentou como principal resultado a entrada e a permanência da dengue na pauta da mídia, o estabelecimento da relação entre os níveis estadual e municipal no enfretamento da doença, além da maior comunicação entre grupos importantes na prevenção e no controle da dengue frente à comunidade e na disseminação de informações sobre a prevenção da doença.

O contexto municipal foi visto como obstáculo para o alcance dos resultados esperados. Por outro lado, é o único capaz de garantir a manutenção da rede. Um paradoxo fundamental a ser equacionado. Também ressalta-se como lacuna do presente estudo que este não teve como objeto o aprofundamento da relação das categorias de governo municipal com o êxito das ações de mobilização social para prevenção e controle da dengue. Ademais, este trabalho deteve-se no estudo da avaliabilidade e na descrição do 
funcionamento do projeto na prática, sendo necessários outros estudos sobre implantação para melhor compreender tal processo.

Como pontos para melhoria destacaram-se a dificuldade na conquista de parcerias locais (como com os comerciantes dos bairros trabalhados), a participação efetiva da comunidade, compreendendo que o causador do problema também é a população; a promoção de mais eventos, como feiras de saúde, palestras com a comunidade, caminhadas, reuniões nos colégios; pouca participação do poder público em ações como faxinaços, pois atividades inerentes a esse setor, como coleta de lixo e retirada de entulhos, foram realizadas pelos articuladores; maior envolvimento da Secretaria de Saúde, enquanto instituição; participação da Prefeitura nos faxinaços, limpando ruas, esgotos, canais, lixões. Para a continuidade do projeto, entre as sugestões, encontra-se a contratação de estagiários.

Neste sentido, foram recomendados: a continuidade das ações de comunicação social e de motivação da equipe, análise prévia do contexto municipal nos aspectos político e sanitário; fortalecimento das estruturas já existentes do PCD, como o Comitê Municipal da Dengue; fortalecimento da participação social; deslocamento do produtor social da rede. Do ponto de vista da teoria, da Flem e Sesab como atuais produtores sociais para a gestão municipal, incluindo as secretarias relacionadas e o coordenador local. Os editores passariam dos atuais coordenadores municipais para os articuladores.
Para os reeditores, dos atuais articuladores para a população local, com mapeamento de lideranças. A Flem teria um papel de animador da rede, capacitação dos coordenadores e articuladores, bem como atuaria nas atuais funções de comunicação social e ampliação das ações de monitoramento do Sismob.

Outras recomendações perpassaram a flexibilização da metodologia, de acordo com a realidade local, com vistas ao objetivo de formar a rede local; redução do número de municípios por equipe animadora (Flem), para permitir o monitoramento da rede de mobilização social; ampliação da capacitação dos articuladores com maior carga horária e, também, ajustes na proposta pedagógica, com um modelo mais participativo; retirar a centralidade dos faxinaços, revendo sua meta anual, e incluir a formulação dos Planos de Ação por bairro como ação importante no Sismob; trabalhar com números mais flexíveis com relação à quantidade de articuladores por bairro; os relatórios técnicos de viagem devem ser como resumos executivos que reflitam a realidade municipal; uso do potencial do Sismob para monitoramento e avaliação da intervenção.

\section{Colaboradores}

Chaves, S. C. L.; Silva, G. A. P. e Rossi, T. R. A. conceberam o projeto, procederam à coleta de dados, analisaram e escreveram todo o trabalho. 


\section{Referências}

AL-MUHANDIS, N.; HUNTER, P. R. The value of educational messages embedded in a community-based approach to combat dengue fever: a systematic review and meta regression analysis. PLoS Negl Trop Dis, California, v. 5, n. 8, p. e1278, ago. 2011.

BALLENGER-BROWNING, K. K.; Elder, J. P. Multimodal Aedes aegypti mosquito reduction interventions and dengue fever prevention. Trop Med Int Health, Oxford, v. 14, n. 12, p. 1542-1551, dez. 2009.

BHATT, S. et al. The global distribution and burden of dengue. Nature, London, v. 496, n. 7446, p. 504-507, abr. 2013.

DONABEDIAN, A. Explorations in Quality Assessment and Monitoring: the definition of quality and approaches to its assessment. Ann Arbor: Health Administration Press, 1980.

FERREIRA, I. T. R. N.; VERAS, M. A. S. M.; SILVA, R. A. Participação da população no controle da dengue: uma análise da sensibilidade dos planos de saúde de municípios do Estado de São Paulo, Brasil. Cad. Saúde Pública, Rio de Janeiro, v. 25, n. 12, p. 2683-2694, dez. 2009.

FLAUZINO R. F.; SOUZA-SANTOS, R.; OLIVEIRA,

R. M. Dengue, geoprocessamento e indicadores socioeconômicos e ambientais: um estudo de revisão. Rev Panam Salud Publica, v. 25, n. 5, p. 456-61, maio 2009.

FUNDAÇÃO LUIS EDUARDO MAGALHÃES (FLEM). Construção da mobilização social: manual do passo a passo. Bahia: Flem, 2010.

INOJOSA, R. M. Redes de compromisso social. Revista de Administração Pública, Rio de Janeiro, v. 33, n. 5, p. 115-141, 1999.

LIMA, E. C.; VILASBOAS, A. L. Q. Implantação das ações intersetoriais de mobilização social para o controle da dengue na Bahia, Brasil. Cad. Saúde Pública, Rio de Janeiro, v. 27, n. 8, ago. 2011.
MEDINA, M. G. et al. Usos de modelos teóricos na avaliação na avaliação em saúde: aspectos conceituais e operacionais. In: HARTZ, Z. M. A. Avaliação em saúde: dos modelos teóricos à prática na avaliação de programas e sistemas de saúde. Rio de Janeiro: Fiocruz, 2005, p. 41-63.

MELO, M. S. S. et al. Progressão da circulação do vírus do dengue no Estado da Bahia, 1994-2000. Rev. Soc. Bras. Med. Trop., Uberaba, v. 43, n. 2, p. 139-144, abr. 2010.

PATTON, M. Q. Qualitative research \& evaluation methods. London: SAGE Publications, 2002.

PIMENTA-JÚNIOR, F. G. Desenvolvimento e validação de um instrumento para avaliar o Programa Nacional de Controle da Dengue no âmbito municipal. 2005. 210 f. Dissertação (Mestrado em Saúde pública) - Escola Nacional de Saúde Pública, Fundação Oswaldo Cruz, Rio de Janeiro, 2005.

RANGEL, S. M. L. Dengue: educação, comunicação e mobilização na perspectiva do controle - propostas inovadoras. Interface, Botucatu, v. 12, n. 25, p. 433-441, abr./jun. 2008.

ROSSI, P. H.; LIPSEY, M. W.; FREEMAN, H. E. Evaluation, a systematic approach. Beverly Hills: Sage, 2004.

ROSSI, T. R. A.; CHAVES, S. C. L. Implementação da atenção especializada em saúde bucal em dois municípios na Bahia/ Brasil. Saúde debate, Rio de Janeiro, v. 39, p. 196-206, dez. 2015.

SALES, F. M. S. Ações de educação em saúde para prevenção e controle da dengue: um estudo em Icaraí, Caucaia, Ceará. Ciênc. saúde coletiva, Rio de Janeiro, v. 13, n. 1, p. 175-184, fev. 2008.

SANCHEZ, L. et al. Intersectoral coordination in Aedes aegypti control: a pilot project in Havana City, Cuba. Tropl Med Int Health, Oxford, v. 10, p. 82-91, jan. 2005. 
SANTOS, D. et al. Documento de posição sobre a tríplice epidemia de Zika-Dengue-Chikungunya. Bahia: UFBA, 2016. Disponível em: <https://www.abrasco.org. br/site/wp-content/uploads/2016/03/Documentoposi\%C3\%A7\%C3\%A3o-sobre-a-epidemia-de-zika. pdf>. Acesso em: 14 nov. 2016.

SIMMONS, C. P. et al. Dengue. N Engl J Med, Boston, v. 366, n. 15, p. 1423-1432, abr. 2012.

TAUIL, P. L. Aspectos críticos do controle do dengue no Brasil. Cad. Saúde Pública, Rio de Janeiro, v. 18, n. 3 , p. 867-871, jun. 2002.

TEIXEIRA, M. G. et al. Avaliação de impacto de ações de combate ao Aedes aegypti na cidade de Salvador, Bahia. Rev. bras. epidemiol., São Paulo, v. 5, n. 1, p. 108115, abr. 2002.
TEIXEIRA, M. G. et al. Dengue: twenty-five years since reemergence in Brazil. Cad. Saúde Pública, Rio de Janeiro, v. 25, n. 1, p. S7-S18, 2009.

TORO, J. B.; WERNECK. N. M. D. Mobilização social: um modo de construir a democracia e a participação. Brasília, DF: Unicef, 1996.

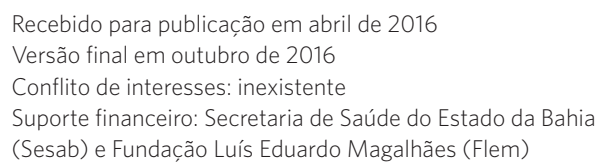

